\title{
Biosorption of Arsenic (III) by Using Lemon Peel Powder as Low Cost Effective Biosorbent
}

\author{
Vijayarani.A* \\ St.Ann's Degree college for women, Mehdipatnam, Hyderabad School, T.S, India \\ Dr.Sailaja.B.B.V \\ Head of the Department of inorganic and analytical chemistry, \\ Andhra University. Visakhapatnam, India \\ Dr.Sirisha.D \\ St.Ann's Degree College for women, Mehdipatnam, Hyderabad
}

\begin{abstract}
:
The use of lemon peel powder, a novel, low-cost, and sustainable biosorbent derived from food waste, to remove arsenic has largely gone unexplored. The feasibility and viability of the As (III) biosorption abilities of lemon peel powder are compared in this study. The parameters such as contact time, $\mathrm{pH}$, the amount of lemon peels used, the initial arsenic concentration, and temperature all had an effect on the sorption process. Thermodynamic, kinetic, and equilibrium were all evaluated. The optimal $\mathrm{pH}$ was 6.0 , and it lasted until $\mathrm{pH} 8$ with $72.34 \%$ removal efficiency. Lemon peel (LP) has a $\mathrm{pH}$ PZC value of 7 and a surface $\mathrm{pH}$ of 7 . The analysis of kinetics revealed that the biosorption was regulated by a second-order reaction, as well as the fact that the catalytic region of the biosorbent was heterogeneous; however, the biosorption process was better defined by the Freundlich and Temkin isotherms. Finally, it is possible to remove arsenic (III) using waste content. Thermodynamic and equilibrium analysis have shown that sorption is a natural process that is spontaneous, beneficial, and endothermic. In addition, Fourier Transfer Infrared Spectroscopy (FTIR) research shows that arsenic reacts with metal oxides and the $-\mathrm{OH}$ functional group in lemon peel. These findings indicate that this peel can be used to remove arsenic from a simulated aqueous solution as a valuable, low-cost sorbent. This research lays the groundwork for the potential production of an effective filtration device that uses citrus peel powder as a lowcost, innovative, and long-lasting biosorbent to treat water polluted with arsenic (III).
\end{abstract}

Keywords: Arsenic, Equilibrium, FTIR, Isotherms, Kinetic, PZC, Thermodynami

DOI: $10.7176 / \mathrm{JNSR} / 12-14-01$

Publication date:July $31^{\text {st }} 2021$

\section{Introduction:}

Arsenic is found naturally in the earth's layers, but it is also mobilised into ground and marine water as a result of human activities such as pesticide and herbicide use [2,33]. Arsenic is one of the World Health Organization's top ten chemicals to be concerned about. Arsenic in drinking water does not exceed $10 \mu \mathrm{g} / \mathrm{L}$ according to WHO guidelines. According to recent survey results, higher levels of arsenic in ground water can be found in many areas of eastern Uttar Pradesh and Bihar, posing a health risk [9]. Arsenic poisoning causes severe health problems in people [12]. Arsenic remediation is a global issue that can be solved to a large degree using many traditional methods that are very costly and time consuming, dangerous to staff, and by product disposal is not safe experimentally $[9,14]$. Arsenic remediation needs a cost-effective, environmentally sustainable solution right now.

The passive absorption of heavy metals by natural or dead biomass is known as biosorption. Biosorption is a cutting-edge technique for removing radioactive metals from contaminated streams. It makes use of natural materials like agricultural residues[15], forestry waste products [16], food waste materials, and fruit peel[18]. For heavy metal decontamination, natural materials have a high potential. The existence of carboxylic, phosphate, sulphate, amino, amide, and hydroxyl groups, which are typically found in cell walls, is attributed to the metal entrapment property of these residues,[20,23] Several factors influence biosorption, including contact time, dosage, $\mathrm{pH}$, temperature, the presence of other metals in the same solution, the type of biosorbent material used, and so on. Complexation, coordination, chelation, ion exchange, adsorption, and inorganic micro precipitation are all involved in metal ion absorption through biosorption, which is dependent on the substrate[24].

The bioaccumulation of heavy metals is believed to be caused by a variety of biomolecules, proteins, and polysaccharides [25,26], [31]. Citrus peel would also have increased metallic ion biosorption potential due to the existence of a large number of $-\mathrm{OH}$ and $-\mathrm{COOH}$ functional groups found through FTIR research. Living plants' biosorption ability appears to be a two-stage process, with the first phase being rapid and the second phase being sluggish. Surface adsorption (physical and chemical), diffusion into particles, and adsorption and fixation are all stages in the adsorption process by plant materials. The removal of arsenic from lemon peel powder was $90 \%$ in 
the adsorbents screening test, with a surface area of $21.2 \mathrm{~cm}^{2}$ and an arsenic removal $4.24 \%$ per sq.cm. As a result of this proof, lemon peel powder was chosen as the biosorbent for the research study.

\section{1: Objectives:}

a) To design a regulating technology for the adsorption of arsenic from aqueous solution.

b) To design an arsenic-removal water filter.

c) To design a low-cost, environmentally friendly Arsenic adsorption technology.

\subsection{Lemon Peel Powder Characterization:}

In lemon peel powder, FTIR analysis shows the existence of carboxyl groups $\mathrm{C}-\mathrm{O}$, organic compounds like Hydrocarbons $\left(\mathrm{C}_{\mathrm{X}} \mathrm{H}_{\mathrm{Y}}\right)$, Hydroxyl groups, carbonyl $\mathrm{C}=\mathrm{O}$, alcohol $\mathrm{C}-\mathrm{OH}$ group, pectin, hemicellulose, and lignin, as well as carboxyl groups $\mathrm{C}-\mathrm{O}$, organic compounds like Hydrocarbons $\left(\mathrm{C}_{\mathrm{X}} \mathrm{H}_{\mathrm{Y}}\right)$, Hydroxyl groups, carbonyl $\mathrm{C}=\mathrm{O}$, alcohol $\mathrm{C}-\mathrm{OH}$ group, pectin, Arsenic oxides react with functional groups present in biosorbent [32] based on the stretching and bending vibrations of these functional groups during biosorption.

Lemon peel contains carbon-rich biochar that can be used for a variety of processes and can also be used as a biosorbent due to its porous nature [33].

The peaks were observed after the As (III) ions adsorption process, and the peaks gradually faded due to the interaction of the As ions molecules with the functional groups present on the biomass surface. As a result, the hydroxyl group and carboxylic acid may play a role in the removal of Arsenic metal.

\subsection{Charecterization of Lemon peel before and after adsorption:}

SEM analysis of lemon peel powder before adsorption revealed that the surface of lemon peel powder is typically asymmetrical, highly porous with larger number of pores [8]. The surface of the biomaterial is irregular and porous allowing a better heterogeneous biosorption due to the large interface moreover, it presents small white spots which indicate the presence of Calcium, Aluminium and Potassium in its structure [1].

\subsubsection{SEM interpretation after adsorption:}

From high magnification SEM photographs of the cross section of lemon peel, the surface of the lemon peel was found to be unsymmetrical, irregular, fibrous, with pores of various sizes, and highly porous in nature, according to SEM studies [29,30], [8-11], [1,13]. All of the research done on lemon peel has shown its adsorption potential, indicating that it can be used as a low-cost, environmentally friendly adsorbent. After the adsorption of arsenic by lemon peel, SEM studies were carried out at different resolutions/ magnifications, as shown in Fig-1(a), (b), (c), (d), (e).
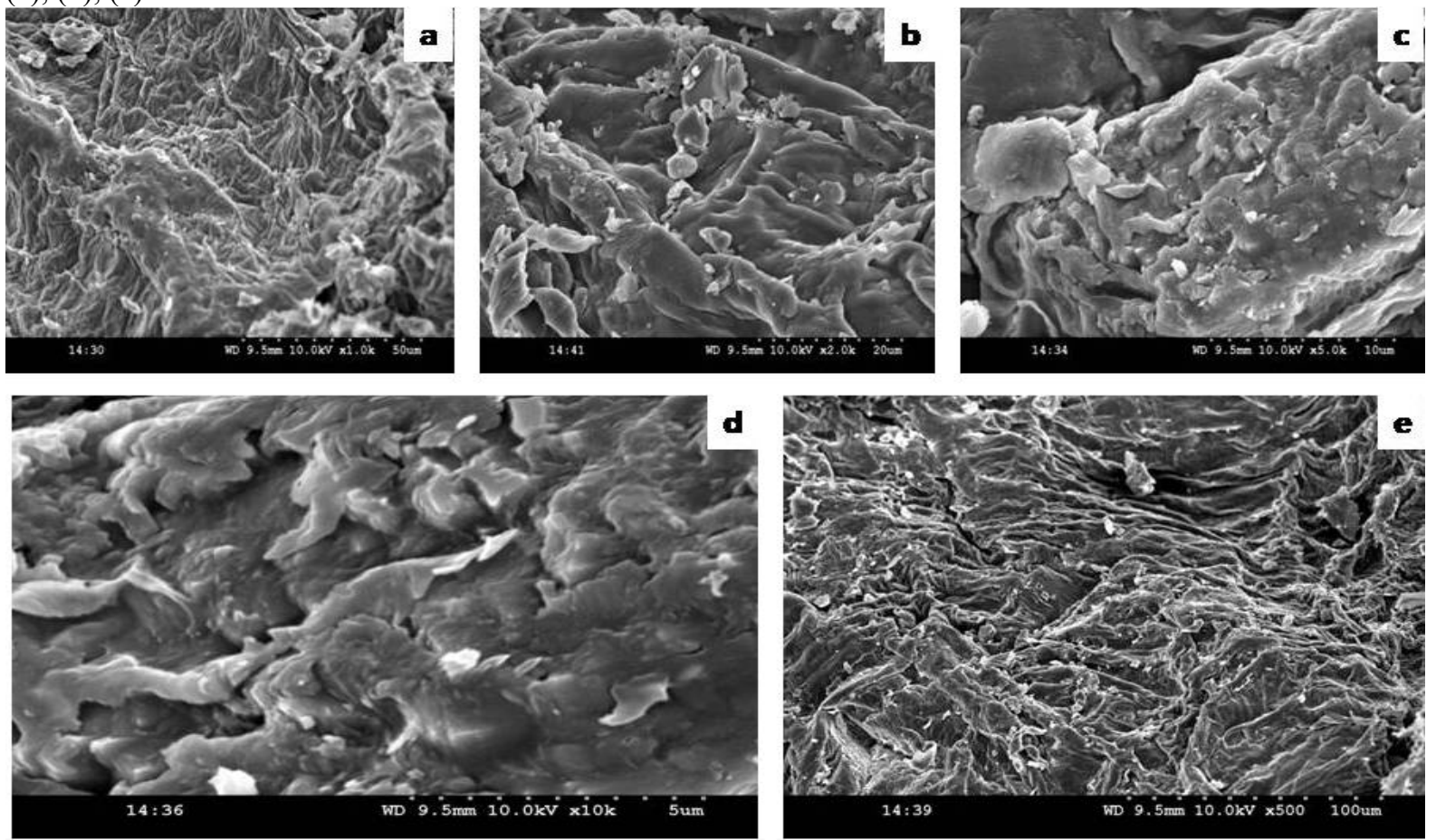

Figure-1: Scanning electorn microscopy (SEM) images after adsortpion: (a) Light and dark shaded clusters showing the arsenic molecules attaching to the fibrous surface. (b) Reveals the shapes/cross sections of heterogeneous surfaces of adsorbent which show a mixture of small and large particles, with two distinct stages, spherical, unsymmetrical, uneven, and various forms of shapes. (c) Layered/Fibrous surface with pore 
morphology on biomaterial is observed confirming the binding/chelation of molecules to the lemon peel portion. (d) The surface has a wavy nature with various aberrations and hollow pores and a light/dark shaded surface signifying the presence of arsenic molecules. (e) Agglomeration has been observed as a result of chelates formation and two separate phases on the biomaterial are seen with sponge-like porous and thread-like fibrous structures.

\subsubsection{FTIR spectral analysis of lemon peel before and after adsorption:}

The FTIR is a critical tool for understanding biosorbent biosorption behaviour. By analyzing the FTIR spectra of lemon peel before and after adsorption, the biosorption of arsenic molecules can be clarified. According to previous studies [36] the presence of hydroxyl/ bonded -OH groups in the range of 3949-1, 3987.8, and 3934.2 $\mathrm{cm}^{-1}$ in the molecular structure of lemon peel before adsorption is suggested by the stretching of hydroxyl groups in the range of 3949-1, 3987.8, and $3934.2 \mathrm{~cm}^{-1}$ in the molecular structure of lemon peel. All citrus based peels display vibrations in the range of 3600-3700 cm-1, which characterize intra and inter hydrogen bonding, O-H stretching bonding, and the presence of ternary amines that have been moved by widening or a spike change, indicating arsenic ion adsorption by lemon peel. Before adsorption, adsorption peaks in lemon peel were seen in the range of $2933-2928 \mathrm{~cm}^{-1}$, which can be related to the stretching asymmetric vibration of the $\mathrm{CH}$ group (methoxy and aliphatic hydrocarbons), which were widened to $2551.4 \mathrm{~cm}^{-1}$, indicating the chelation of arsenic ions with the functional groups of lemon peel.

In lemon peel, the picture of $\mathrm{COOH}$ and $\mathrm{COOCH}_{3}$ vibrations/absorption peaks is attributed to about 1700$1750 \mathrm{~cm}^{-1}$. The peaks have widened to $1923.7,1869.7 \mathrm{~cm}^{-1}$ after adsorption, and the FTIR spectral behaviour has changed. Before adsorption (carbonate ion vibrations), $1420 \mathrm{~cm}^{-1}$ and $1430 \mathrm{~cm}^{-1}$ peak can be seen, which are moved after adsorption to $1278.5,1243.1 \mathrm{~cm}^{-1}$. The finger print area of lemon peel fibre is located between 800 and $1200 \mathrm{~cm}^{-1}$. C-O-C stretching and $\mathrm{O}-\mathrm{H}$ bonding has been significantly altered in response to $\mathrm{CH}_{3}$ deformation. These peaks, 1278.5, 1243.1, and $782.7 \mathrm{~cm}^{-1}$, suggested that the fibre nature/structure of lemon peel promoted arsenic adsorption. There is evidence of $\mathrm{NO}_{2}$, Carbon- Carbon $(\mathrm{C}=\mathrm{C})$ bonding, and Carbon- Oxygen $(\mathrm{C}-\mathrm{O})$ bonding in the sugar components of lemon peel. The bonding of arsenic ions with the established active centres was revealed by FTIR studies.

FTIR is the essential tool user for explaining the biosorbent biosorption behaviour. The biosorption of lemon peel in adsorption of arsenic molecules is explained by interpreting FTIR spectra of lemon peel before and after adsorption. From the previous studies [36] the lemon peel (raw) has characteristic peaks in the range of $3300-3400 \mathrm{~cm}^{-1}$ before adsorption indicates the presence of hydroxyl/ bonded $-\mathrm{OH}$ groups which is indicated of the stretching of hydroxyl groups in the range of 3949-1, 3987.8, and 3934.2 in the molecular structure of lemon peel. Vibrations are shown in the range of $3600-3700 \mathrm{~cm}^{-1}$ in all citrus based peels which characterize intra, inter hydrogen bonding, $\mathrm{O}-\mathrm{H}$ stretching bonding and presence of ternary amines which have been shifted by widening or a spike shift is observed which indicates the adsorption of arsenic ions by lemon peel. Adsorption peaks are seen in the range of 2933-2928 $\mathrm{cm}^{-1}$ in lemon peel before adsorption which can be assigned to stretching asymmetric vibration of $\mathrm{CH}$ group (methoxy and aliphatic hydrocarbons which were widened to $2551.4 \mathrm{~cm}^{-1}$ indicating the chelation of arsenic ions with the functional groups of lemon peel.

The image of vibrations/absorption peaks for $\mathrm{COOH}$ and $\mathrm{COOCH}_{3}$ is attributed around $1700-1750 \mathrm{~cm}^{-1}$ in lemon peel. After adsorption the peaks have widened to 1923.7, 1869.7 and there is modification in the FTIR spectral behaviour. $1420 \mathrm{~cm}^{-1}, 1430 \mathrm{~cm}^{-1}$ peaks are seen before adsorption (carbonate ion vibrations) which are shifted after adsorption $\left(1278.5,1243.1 \mathrm{~cm}^{-1}\right)$. The region $800-1200 \mathrm{~cm}^{-1}$ represents the finger print region of lemon peel fibre. Corresponding to $\mathrm{CH}_{3}$ deformation $\mathrm{C}-\mathrm{O}-\mathrm{C}$ stretching and $\mathrm{O}-\mathrm{H}$ bonding which has modified to great extent. Three peaks $1278.5,1243.1,782.7 \mathrm{~cm}^{-1}$ indicated the lemon peel promotion for the arsenic adsorption with fibre nature/ structure of lemon peel. Involvement of $\mathrm{NO}_{2}$, Carbon- Carbon $(\mathrm{C}=\mathrm{C})$ bonding Carbon- Oxygen (C-O) of sugar components of lemon peel is observed as reported in Fig-2. FTIR studies revealed the bonding of arsenic ions with the identified active centres.

2.1.3. XRD image analysis: Sharp peaks indicated amorphous nature, while peaks between 20 and 22 displayed the fibrous nature of lemon peel on the XRD graph shown in Fig-3.

\subsection{Results and Discussion}

\subsection{Contact time - Arsenic Biosorpiton:}

The experiment was carried out with a $50 \mu \mathrm{g} / \mathrm{L}$ arsenic concentration and a dosage of 1 gm lemon peel powder to determine the time required for the removal of arsenic species, and the plot of biosorption percentage and biosorption time revealed that the rapid removal of arsenic species was observed from 20 min to $40 \mathrm{~min}$, with the rate stabilizing at $40 \mathrm{~min}$, which is considered the optimum contact time as shown in Fig-4. Since there was more surface area available for metal biosorption during these minutes, the arsenic metal ratio was higher. Later, due to the sheathing of lemon peel powder particles around the binding sites, the binding sites become very limited, which may be due to the development of centrifugal forces between the arsenic on the solid surface and the liquid phase[34]. 


\subsection{Lemon peel Dosage:}

To research the arsenic biosorption percentages, lemon peel powder was used in variable dosages of $0.5,1.0,1.5$, 2.0, 2.5, and $3.0 \mathrm{gm}$ as biosorbent with initial Arsenic concentrations and a fixed contact period of 40 minutes. The high efficiency in Arsenic removal was found with gradual increases in dosages from 0.5 to 3.0 gm due to the availability of more functional groups on the biosorbent surface, and the decrease in biosorption capacity could be associated with the reduction in available sites as biosorbent particles agglomerated at higher doses. The optimum dosage of lemon peel powder is 2.0 gm as shown in Fig-5.

The statistical analysis of FTIR spectra of lemon peel powder revealed a possible connection between biosorbent efficiency and the chemical structures of the biosorbent surfaces. Higher levels of $-\mathrm{OH}$ of alcohols, phenols, and lower amounts of carboxylic acids of $\mathrm{C}-\mathrm{H}, \mathrm{C}-\mathrm{O}-\mathrm{C}, \mathrm{C}-\mathrm{N}$, and $\mathrm{P}-\mathrm{O}$ of polysaccharides and $\mathrm{C}=\mathrm{C}$ of lipids, lignin moieties resulted in more potential in arsenic biosorption at higher dosages due to higher affinities to $-\mathrm{OH}$ of alcohol groups and other above functional groups due to the availability of more functional groups.

\subsection{Arsenic initial Concentration:}

When the initial concentration of As (III) was changed, the biosorption potential of lemon peel powder changed, with the optimal contact time 20 minutes and dosage $2.0 \mathrm{gm}$. The As (III) biosorption potential of Lemon peel powder was enhanced when the original As (III) concentration was increased from $10 \mu \mathrm{g} / \mathrm{L}$ to $60 \mu \mathrm{g} / \mathrm{L}$. (Fig-6). The biosorption potential of this biosorbent did not significantly increase when the original As (III) concentration was increased to $80 \mu \mathrm{g} / \mathrm{L}$. In lemon peel powder, the optimal initial concentration of As (III) (in terms of biosorption efficiency) was discovered to be $60 \mu \mathrm{g} / \mathrm{L}$. The availability of less biosorption sites on the surface of the lemon caused saturation of As (III) biosorption at higher initial concentrations [20].

Higher As (III) mass transfer at the surface of the biosorbent [21] accounts for the higher biosorption potential at higher initial As (III) concentrations. The results show that the biosorption ability of lemon peel was unaffected by As metal ions capture and may provide structural integrity that aids in the development of an effective As (III) removal filtration technology using bio sorbents.

\subsection{Effect of $\mathbf{p}^{\mathrm{H}}$ on Arsenic biosorption:}

In arsenic (III) metal speciation in solution, the operational parameter $\mathrm{pH}$ is critical for adsorption studies. The $\mathrm{pH}$ parameter is used to determine the ionization state of functional groups on the biosorbent surface. The increase in As (III) biosorption potential was triggered by increasing the $\mathrm{pH}$ range from 2 to 6 . In Fig-7, the rate of biosorption remained constant from 6 to 8. As a result, the optimal $\mathrm{pH}$ for lemon peel was determined to be 6 with a $72 \%$ removal rate. Arsenic adsorption decreases as $\mathrm{pH}$ rises, i.e., in an alkaline medium, the same findings were found in one of the literatures [3,5]. This could happen because the biosorbent's net surface charge is negative, decrease the biosorption rate. The $\mathrm{pH}$ pzc of lemon peel was found to be nearly neutral $[6,17]$ ranging from 6 to 6.91, resulting in an increase in carboxyl content due to saponification of protein and other organic matter in the adsorbent.

Since functional groups including carboxyl and hydroxyl on the biosorbent are more accessible when the $\mathrm{P}^{\mathrm{H}}$ of arsenic solution reaches the $\mathrm{p}^{\mathrm{H}} \mathrm{PZC}$ value (neutral) of Lemon peel, the arsenic biosorption rate increases.

Because of the ligands of the biosorbent, the movement of metal cations to the biosorbent surface is limited at lower $\mathrm{pH}$ 1.0-4.0, and there may be a close association with hydronium ions [19].

The biosorption rate in the acidic medium is lower before $\mathrm{pH} 5.0$ due to protonation of functional groups such as carboxyl and hydroxyl present on biosorbent. From $\mathrm{pH} 6.0$ to 8.0, the functional groups deprotonate, increasing the negative charge density on the biosorbent surface and increasing the biosorption rate.

This can also be shown in the following way: As the $\mathrm{pH}$ rises, the solubility of the Arsenic metal ion decreases, resulting in a lower degree of hydration of the metal ions (less energy required for removal of water molecules related to hydration with metal ion) reported similar findings in their PFB1 analysis by Suhasini et al [19].

\subsection{Biosorption of arsenic at different temperatures:}

The arsenic biosorption is investigated at various temperatures ranging from $20^{\circ} \mathrm{C}$ to $80^{\circ} \mathrm{C}$ using various Arsenic concentrations. As shown in Fig-8, the quality of arsenic biosorption has improved, resulting in $42 \%$ to $82 \%$ elimination. According to the biosorption principle, as the temperature rises, desorption of adsorbed molecules from the surface of the sorbent occurs, resulting in a decrease in the biosorption rate. In the paper Cd (II) biosorption on C.Vulgaris; the same conclusion was reached.

\subsection{Isotherms of biosorption:}

The position of As (III) biosorption by lemon peel powder was identified by using isotherm models such as Langmuir, Freundlich, and Temkin to analyze the best-fitting equilibrium data when solute biosorption occurs by monolayer biosorption, and it can also interpret arsenic biosorption using the biosorbent lemon peel powder. 


\subsubsection{Isotherm of Langmuir Biosorption:}

Table-1 shows a negative slope between ce and ce/qe, indicating that the biosorption of As (III) did not obey the Langmuir isotherm model. This meant that arsenic biosorption did not occur in a monolayer and that the arsenic biosorption could not be interpreted. Correlation coefficients $\left(\mathrm{R}_{2}\right)$ are lower in this model than in other isotherm models. Figure-9 shows that the Arsenic biosorption on lemon peel powder did not fit into the Langmuir biosorption isotherm model.

\subsubsection{Isotherm of Freundlich Biosorption:}

The plots of ce versus qe show that As (III) biosorption follows the Freundlich isotherm model, implying that As(III) sorption on the surface of biosorbent occurs in heterogeneous layers. This was made possible by converting carboxylic acid groups to Na carboxylic acid with an alkali treatment, resulting in improved affinity and binding ability for successful biosorption. As a result, $\mathrm{R}_{2}$ values ranged from 0.999 to 0.991 (Table-1), and the linearized form of the Freundlich Isotherm can be seen in Fig-10. The $\mathrm{K}_{\mathrm{f}}$ values for lemon peel are 0.5 and $0.6 \mathrm{mg} / \mathrm{g}$, while the $\mathrm{n}$ values are greater than $1(\mathrm{n}<1)$, indicating a dynamically favourable state for As (III) biosorption on the biosorbent surface.

Nevertheless, the biosorbed As (III) reformed the biosorbent surface at the time of initial biosorption, making it more conducive to subsequent biosorption [21,22]. This finding is consistent with previous research on Se (IV) fitted to Freundlich on a variety of sorbents, including layered double hydroxide (LDH) nanoparticles and iron oxide impregnated carbon nanotubes [4,27]. Lemon peel powder has a high ranking and maximum biosorption potential, according to the current literature.

\subsection{3.. Isotherm of Temkin Biosorption:}

As lines were passed from the y-axis that is close to origin, the Arsenic adsorption slightly fitted to the Temkin biosorption isotherm, as shown in Fig-11. As shown in Table-1, the correlation coefficient values are higher than Freundlich and not lower than Langmuir. As a result, Temkin Isotherm can be used to interpret Arsenic biosorption to some degree.

\subsection{Kinetics of biosorption Isotherm:}

Kinetic experiments are carried out to investigate Arsenic biosorption kinetics using pseudo first and second order kinetics, Elovich and intra particle diffusion, or the Weber-Morris model. The statistical data provided in this analysis will determine the most appropriate model for the current research data.

\subsubsection{Pseudo first and second order kinetics:}

The constant and correlation coefficient values obtained from the kinetic models revealed that pseudo first order kinetics did not control the biosorption mechanism because the lines were not passed through the origin (Fig-12) and $\mathrm{k}_{1}$ values were less than unity (Table-2). As a result, the Arsenic biosorption could not be described by the pseudo first order kinetic model. The correlation coefficients were similar to unity (Table-2) and the lines were nearly parallel to the origin, confirming that arsenic biosorption followed the pseudo second order equation (Fig13). The calculated qe values are in relation to the pseudo second order kinetic's definite values. Several studies have made similar observations [19].

\subsubsection{Elovich and Weber Morris Diffusion Models:}

The Elovich and Weber Morris models were used to examine the better correlation of equilibrium data, but the application of these two models did not result in a straight line passing through the origin, as shown in Fig-14 and 15 , indicating that intraparticle diffusion was not the rate determining phase. Table-2 shows that the Arsenic biosorption onto Lemon peel powder did not follow the Elovich and Weber Morris diffusion model due to the non linearity of both plots and negative slope values.

\subsection{Thermodynamics and the Equilibrium Constant:}

As the temperature ratios increase, such as $273,293,303,313,333 \mathrm{~K}$, the $\Delta \mathrm{G}^{\mathrm{o}}$ values rise, indicating that the biosorption process is endothermic, as shown in table-3 and Fig-16 and 17. The negative value of $\Delta \mathrm{S}^{\circ}$ indicated a decline in randomization $[4,28]$. Since the process is endothermic, these findings showed that high temperatures are needed for Arsenic biosorption onto lemon peel powder. As the temperature rises, the thickness of the boundary layer thickens, resulting in a higher sorption capacity.

The $\mathrm{R}_{\mathrm{L}}$ (Equilibrium constant) of various temperatures was reported as $\mathrm{R}_{\mathrm{L}}>1$, indicating that arsenic bisorption using lemon peel powder is spontaneous and advantageous.

\subsection{Conclusion:}

Due to the higher biosorption potentiality on carboxyl groups, lemon peel powder was investigated as one of the strongest and cheapest biosorbents for the removal of Arsenic ions from solution. The biosorption potential increased with increasing $\mathrm{pH}$ from 6.0 to 8.0, after which it remained constant until $\mathrm{pH} 10.0$, when Arsenic hydroxide precipitation began. The alteration of functional groups and the intensification of peaks were clearly visible in the FTIR spectrum. The increase in the number of grooves seen in the SEM image of Lemon Peel 
explains the increase in biosorption capability. Freundlich isotherm and pseudo-second-order kinetic model were used to model biosorption. Lemon Peel Powder was found to be effective in treating synthetic wastewater that contained a variety of competing ions.

\subsection{Acknowledgement}

I would like to convey my thanks to Dr.B.B.V.Sailaja, the head of the Department of Inorganic and Analytical Chemistry at Andhra University in Visakhapatnam, and Dr.D.Sirisha for their advice, support services, and passion in reporting the findings of this paper, as well as St.Ann's Degree College for Women, Mehdipatnam, Hyderabad, for offering me the lab facilities and materials.

\subsection{Conflict of interest}

The author has no conflict of interest regarding this manuscript.

\subsection{References:}

1. Huang CP, Fu PLK, (1984) Treatment of arsenic (V)-containing water by the activated carbon process. Journal of the Water Pollution Control Federations,; 56: 233-242.

2. Vazquez G, Antorrena G, Gonalez J, Doval MD, (1994) Adsorption of heavy metal ions by chemically modified Pinuspinaster bark. BioresTechnol,; 48: 251-255.

3 Cox M, El-Shafey, Pichugin AA, Appleton Q, In Global Symposium of Recycling, Waste Treatment and Clean Technology (REWAS'99) USA: 1999; 3: 2087-2096.

4. Beveridge TJ, Murray RG, (1980) Sites of metal deposition in the cell wall of Bacillus subtilis. See comment in PubMed Commons below J Bacteriol:; 141: 876-887.

5. Barkley NP, (1991)Extraction of mercury from groundwater using immobilized algae. See comment in PubMed Commons below J Air Waste Manage Assoc: 41: 1387-1393.

6 Ziad T.A.A., Mohammed A.I., and Huda M.M., (2016) Eggshell Powder as An Adsorbent for Removal of $\mathrm{Cu}$ (II) and Cd (II) from Aqueous Solution: Equilibrium, Kinetic and Thermodynamic Studies. Al-Nahrain University, College of Engineering Journal (NUCEJ), Vol.91 No.2, 6192 pp.186 982- 193.

7. Inbaraj, B. S. and Sulochana, N., (2004) Carbonised jackfruit peel as an adsorbent for the removal of Cd (II) from aqueous solution. Bio resource. Technol., 94, 49-52.

8 Sunil K.B., and Arti J. (2010), Removal of copper (II) from aqueous solution using spent tea leaves (STL) as a potential sorbent. Water SA Vol. 36 No. 3, pp. 221- 228. arizmi Engineering Journal: Vol. 12, No. 4, P.P. 117-125.

9. Bakather, O. Y.; Kayvani Fard, A.; Ihsanullah; Khraisheh, M.; Nasser, M. S.; Atieh, M. A. 2017,Enhanced Adsorption of Selenium Ions from Aqueous Solution Using Iron Oxide Impregnated Carbon Nanotubes. Bioinorg. Chem. Appl. No. 4323619.

10. Thirumavalavan, M.; Lai, Y.-L.; Lin, L.-C.; Lee, J.-F. (2010) Cellulose Based Native and Surface Modified Fruit Peels for the Adsorption of Heavy Metal Ions from Aqueous Solution: Langmuir Adsorption Isotherms. J. Chem. Eng. Data:, 55, 1186-1192.

11. Hassan, A. F.; Abdel-Mohsen, A. M.; Elhadidy, H. (2014), Adsorption of arsenic by activated carbon, calcium alginate and their composite beads. Int. J. Biol. Macromol:.68, 125-130.

12. Aksu Z, (2001) Equilibrium and Kinetic modelling of cadmium (II) biosorption by C. vulgaris in a batch system: effect of temperature. Sep Purif Technol: 21:285-294.

13. Suhasini IP, Sriram G, Asolekar SR, Sureshkumar GK, (1999) Biosorptive removal and recovery of cobalt from aqueous systems. Process Biochem: 34:239-247.(26)

14. Bhatnagar A, Minocha AK, Sillanpa“a” M, (2010) Adsorptive removal of cobalt from aqueous solution by utilizing lemon peel as biosorbent. Biochem Eng J:; 48:181-186.

15. Sunil K.B., and Arti J., Removal of copper (II) from aqueous solution using spent tea leaves (STL) as a potential sorbent. Water $S A$ : 2010; Vol. 36 No. 3, pp. 221- 228.

16. Unnithan M. R, Vinod V. P and Anirudhan T. S, (2002) Ability of iron (III) loaded carboxylatedpolysacrylamide-grafted sawdust to remove phosphate ions from aqueous solution and fertilizer industry wastewater: Adsorption kinetics and isotherm studies. J. Appl. Polymer Sci.: 84 (13) 2541-2553.

17. M.R.Mafia et al, (2019) Adsorption of Remazol brilliant blue on an orange peel adsorbent, Brazilian Journal of chemical engineering: 30(3), 657-665.

18. S.A.Singh and S.R.Shukla, Adsorption removal of cobalt ions on raw and alkali treated lemon peels, Int.J.Environ.sci Technol: , 2016; 13, 165-176.

19. Pranav.D.Pathak, Sachin.A. Mandavgene and Bhaskar.D.Kulkarni, 2017, Fruit peel waste characterization and its potential uses, current science:113(10).

20. Lorenzo Massimi et al, 2018, Efficiency evaluation of food waste materials for the removal of metals and 
metalloids from complex multi element solution. Materials:; 11, 334.

21. Elma Sahanovic, Mustafa Hemic, Jasmina Sulejmanovic Alliselavic (2020), Simultaneously adsorption of heavy metals from novel lemon peel based biomaterial, Polish journal of chemical technology: 22(1), 46-53.

22. Dwivedi AK, (2012), Groundwater and Arsenic: A Mini-review. In: Pandey RK (eds.) Environmental Degradation vis-à-vis Biodiversity, New UttamPrakashan, Gorakhpur, 33-48.

23. Dwivedi AK, (2013)Arsenic in Groundwater: An Issue Beyond Boundary, In: Rajkumar D, Lal J. K (eds.) Biodiversity Conservation \& Sustainable Development Centre for Biological Research, Puthalam, Tamil Nadu, India: 30-43.

24. Kumar P, Dara SS, (1982) Utilization of agricultural wastes for decontaminating industrial/domestic wastewaters from toxic metals. Agric Wastes, 4: 213-223.

25. Casarett and Doull's Toxicology, (2008), The Basic Science of Poisons.7th Edition. Klaassen, C.D., ed. McGraw-Hill Publishing Co., Inc., New York.

26. Lahieb F.M, (2016) Batch Sorption of Copper (II) Ions from Simulated Aqueous Solution by Banana Peel. Al-Khw.

27. Ma, Z.; Shan, C.; Liang, J. (2018) Tong, M. Efficient adsorption of Selenium(IV) from water by hematite modified magnetic nanoparticles. Chemosphere, , 193, 134-141.

28. Sheng, G.; Alsaedi, A.; Shammakh, W.; Monaquel, S.; Sheng, J.; Wang, X.; Li, H.; Huang, Y. (2016), Enhanced sequestration of selenite in water by nanoscale zero valent iron immobilization on carbon nanotubes by a combined batch, XPS and XAFS investigation. Carbon: 99, 123-130.

29. .Mihelcic, J. R.; Zimmerman, J. B. (2014), Environmental Engineering: Fundamentals, Sustainability, Design; 2nd ed.; Wiley, p 704.

30. Linda. B.L, (2019) Adsorption of heavy metal Lead(Pb) using citrus grandis leaves as low cost adsorbent, Desalination and water treatment: vol.166, pp 44-52.

31. Revista Facultad de Ingenteria universidad de Antioquia noxx, Adsorption in a binary system of $\mathrm{Pb}$ (II) and $\mathrm{Ni}(\mathrm{II})$ using lemon peels.

32. Dwivedi AK, Srivastava S, Dwivedi S, TripathiVira, (2015), Natural Bioremediation of Arsenic Contamination: A Short Review, Hydrology Current Research , 6: 1.

33. Li, M.; Dopilka, A.; Kraetz, A. N.; Jing, H.; Chan, C. K (2018), Layered Double Hydroxide/Chitosan Nanocomposite Beads as Sorbents for Selenium Oxoanions. Ind. Eng. Chem. Res., 57, 4978-4987.

34. Bakather, O. Y.; Kayvani Fard, A.; Ihsanullah; Khraisheh, M.; Nasser, M. S.; Atieh, M. A. (2017), Enhanced Adsorption of Selenium Ions from Aqueous Solution Using Iron Oxide Impregnated Carbon Nanotubes. Bioinorg. Chem. Appl. No. 4323619.

35. Sachin Arvind. M, Pranav D Pathak, Bhaskar D Kulkarni, Fruit Peel Waste:Characterization and its potential Uses. Current Science:2017;113(3). DOI:10.18520/cs/v113/i03/444-454.

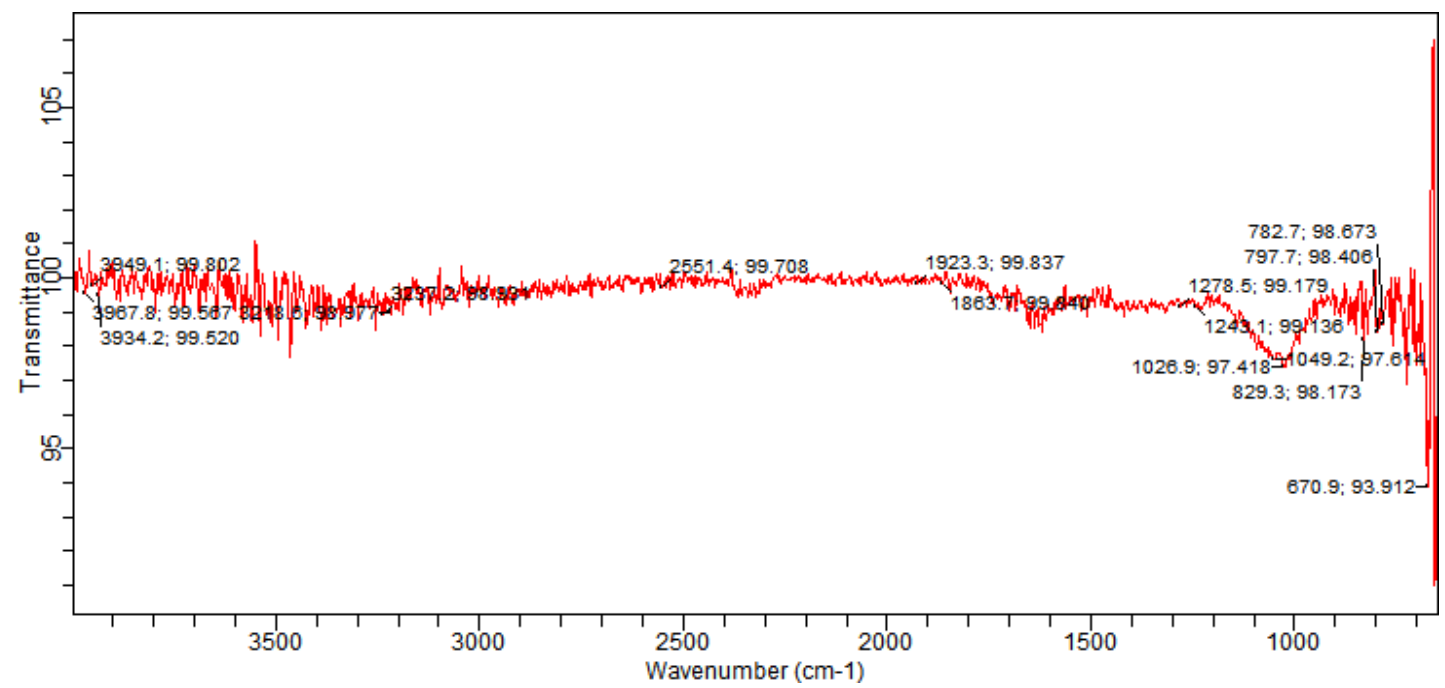

Fig- 2: FTIR image of Lemon peel powder after Arsenic adsorption 


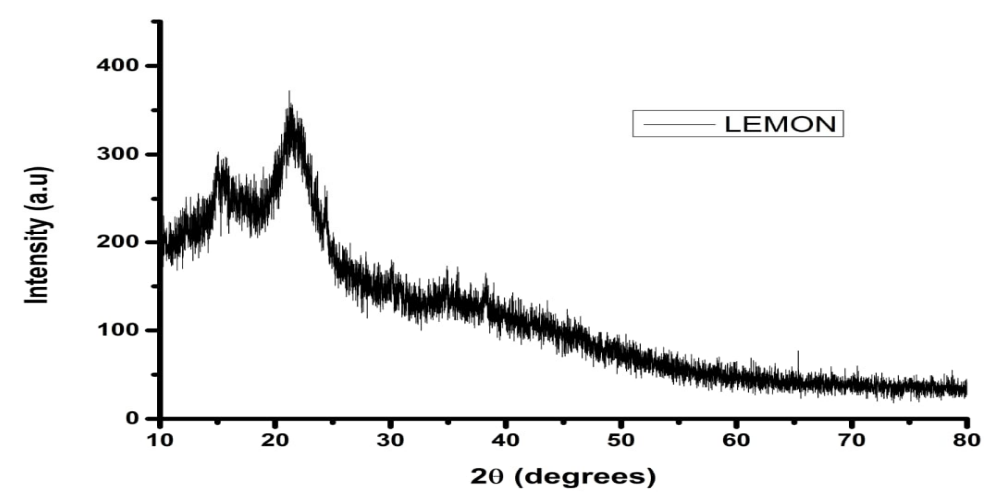

Fig-3: XRD image of lemon peel powder after adsorption

Table-1. Biosorption isotherm constants and their statistical comparison values for Arsenic adsorption by Lemon $\mathrm{F}$ powder

\begin{tabular}{|c|c|c|c|c|c|c|}
\hline \multirow[t]{3}{*}{ SNa } & Patameters & \multicolumn{5}{|c|}{ Lanquili Adsonption Isuthem } \\
\hline & \multicolumn{6}{|c|}{ Temperatune ${ }^{\circ} \mathrm{C}$} \\
\hline & & 0 & 20 & 40 & 60 & 80 \\
\hline \multirow{4}{*}{01.} & $\mathbf{R}^{2}$ & 0.999 & 0.987 & 0.987 & 0.997 & 0.991 \\
\hline & ASS & 0.013 & 0.072 & 0.072 & 0.032 & 0.060 \\
\hline & Q & -0.005 & -0.005 & -0.005 & -0.005 & -0.004 \\
\hline & $\mathbf{b}_{\mathbf{L}}$ & 0.482 & 0.498 & 0.508 & 0.515 & 0.512 \\
\hline & \multicolumn{6}{|c|}{ 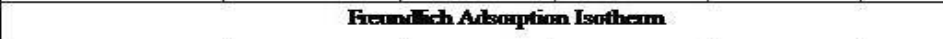 } \\
\hline \multirow{4}{*}{02.} & $\mathbf{R}^{2}$ & 0.927 & 0.928 & 0.912 & 0.985 & 0.985 \\
\hline & ASS & 0.173 & $\mathbf{0 . 1 7 2}$ & $\mathbf{0 . 1 9 1}$ & 0.098 & 0.077 \\
\hline & Logk & 0.507 & 0.568 & 0.547 & 0.639 & 0.657 \\
\hline & Vn & 0.180 & $\mathbf{0 . 1 1 9}$ & 0.159 & 0.061 & 0.054 \\
\hline & \multicolumn{6}{|c|}{ Temkin Adsorptiven Isathem } \\
\hline \multirow{4}{*}{03.} & $\mathbf{R}^{2}$ & 0.888 & 0.903 & 0.888 & 0.945 & 0.954 \\
\hline & ASS & 0.057 & 0.049 & 0.057 & 0.027 & 0.022 \\
\hline & $\mathrm{aT}_{\mathrm{T}}$ & 0.226 & 0.247 & 0.250 & 0.287 & 0.303 \\
\hline & $b_{T}$ & 1.242 & 1.192 & 1.323 & 1.066 & 1.037 \\
\hline
\end{tabular}


Table-3: Kinetic parameters for adsorption of Arsenic by Lemon peel

\begin{tabular}{|c|c|c|c|c|c|c|}
\hline SNa & Panametex & $\begin{array}{c}\text { Arseric } \\
\text { Consenfuation } \\
(10 \mathrm{Ng} / \mathrm{L})\end{array}$ & $\begin{array}{c}\text { Auseries } \\
\text { Consentuation } \\
(20 \mathrm{Hg} / \mathrm{L})\end{array}$ & 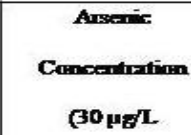 & 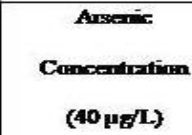 & 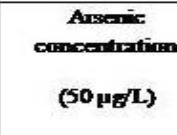 \\
\hline & \multicolumn{6}{|c|}{ 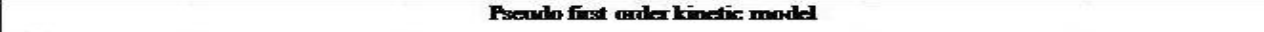 } \\
\hline \multirow[t]{4}{*}{01.} & $\mathbf{R}^{2}$ & 0.907 & 0.902 & 0.974 & 0.986 & 0.986 \\
\hline & Ass & 0.012 & 0.013 & 0.001 & 0.000 & 0.000 \\
\hline & $\mathbf{K}_{\mathbf{1}}$ & 0.006 & 0.006 & 0.004 & 0.003 & 0.003 \\
\hline & \multicolumn{6}{|c|}{ 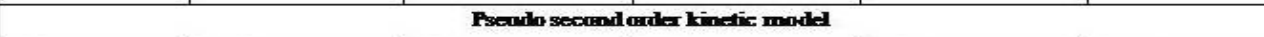 } \\
\hline \multirow[t]{4}{*}{02.} & $\mathbf{R}^{2}$ & 0.914 & 0.890 & 0.871 & 0.897 & 0.842 \\
\hline & ASS & 0.001 & 0.015 & 0.020 & 0.014 & 0.027 \\
\hline & $\mathbf{K}_{\mathbf{2}}$ & 0361 & 0.448 & 0.532 & 1.626 & 1.026 \\
\hline & \multicolumn{6}{|c|}{ Elovichmodel } \\
\hline \multirow[t]{5}{*}{03.} & $\mathbf{R}^{2}$ & 0.981 & 0.984 & 0.980 & 0.955 & 0.928 \\
\hline & ASS & 0.001 & 0.000 & 0.001 & 0.004 & 0.008 \\
\hline & $\alpha$ & -0.159 & 0.156 & -0.145 & -0.112 & -0.107 \\
\hline & $\mathbf{B}$ & 10.83 & 10.10 & 923 & 728 & 637 \\
\hline & \multicolumn{6}{|c|}{ Inturpanticle diffisiunmondel } \\
\hline \multirow[t]{4}{*}{04.} & $\mathbf{R}^{2}$ & 0.954 & 0.949 & 0.963 & 0.960 & 0.957 \\
\hline & Ass & 0.00 & 0.004 & 0.004 & 0.003 & 0.003 \\
\hline & $\mathbf{k}_{\mathrm{ui}}$ & -1538 & -1 sos & -1393 & -1.068 & -1.018 \\
\hline & $\boldsymbol{I}$ & 1433 & 1351 & 1237 & 9.663 & 8.637 \\
\hline
\end{tabular}

Table-4: Thermodynamic parameters of Arsenic adsorption by Lemon peel powder

\begin{tabular}{|c|c|c|c|c|}
\hline S.No- & Telperatiatre & 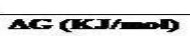 & As (KKI/fad) & 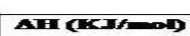 \\
\hline 1 & 273 & -63.55 & -37.14 & 0.086 \\
\hline 2 & 293 & -58.46 & & \\
\hline 3 & 313 & -67.65 & & \\
\hline 4. & 333 & -58.13 & & \\
\hline s- & 353 & 16.95 & & \\
\hline
\end{tabular}

Table-5: Equilibrium parameter $\mathrm{R}_{\mathrm{L}}$ values at different concentrations and temperatures.

\begin{tabular}{|c|c|c|c|c|}
\hline \multirow[t]{2}{*}{ S.No } & \multirow{2}{*}{$\begin{array}{l}\text { Telperature } \\
\text { (ec) }\end{array}$} & \multicolumn{3}{|c|}{ 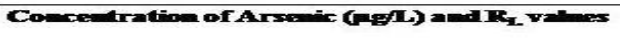 } \\
\hline & & 10pgal & 30pgal & 50, \\
\hline O1. & $\mathbf{0}$ & 0.1005 & 0.033 & 0.200 \\
\hline 02 & 20 & 0.1005 & 0.033 & 0.200 \\
\hline 03 & 40 & 0.1005 & 0.033 & 0.200 \\
\hline 04 & 60 & 0.1005 & 0.033 & 0.200 \\
\hline os & 80 & 0.1004 & 0.033 & 0.200 \\
\hline
\end{tabular}




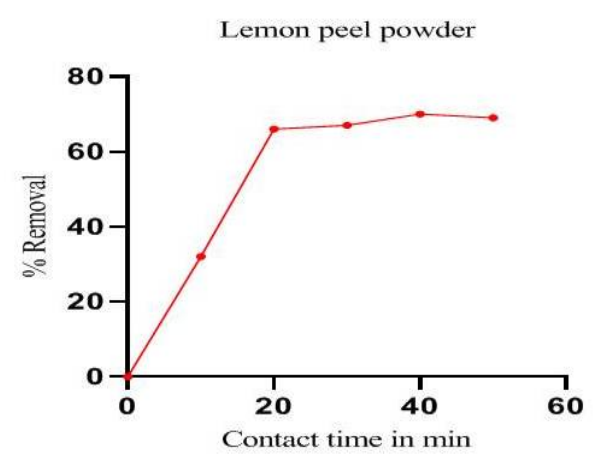

Fig-4: Contact time for Arsenic Biosorption on to Lemon peel powder

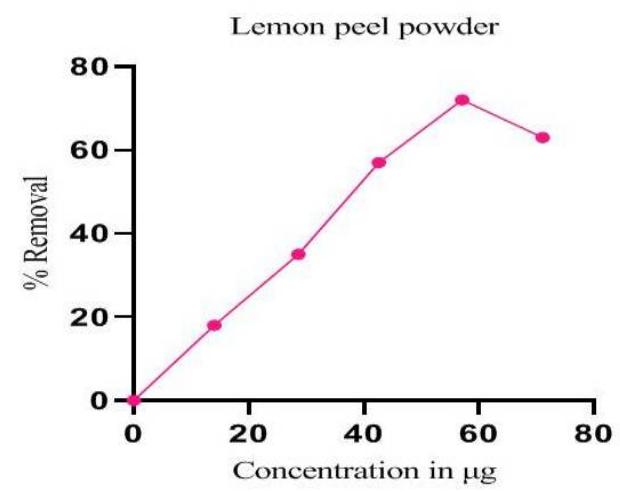

Fig-6: Biosorption of arsenic as a function of concentration

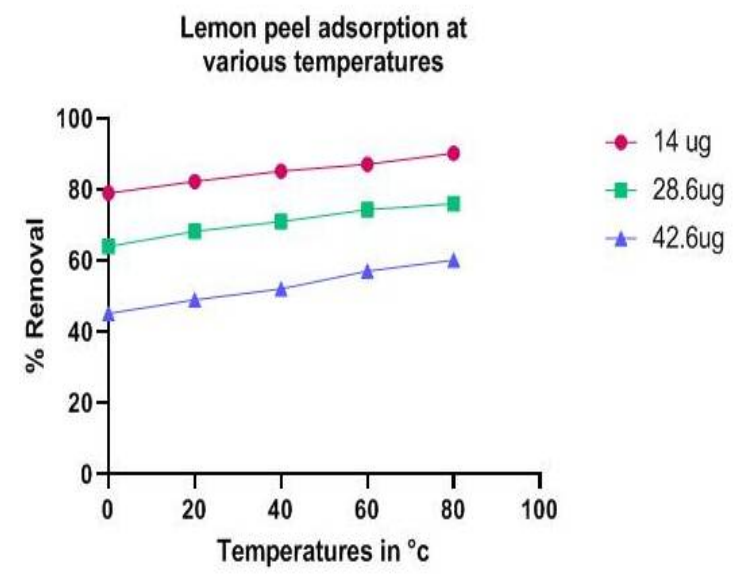

Fig-8: The impact of different temperatures

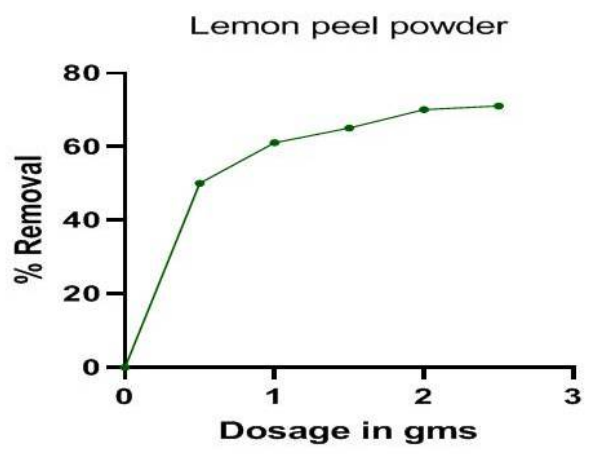

Fig-5: Dosage Effects on Arsenic Biosorption

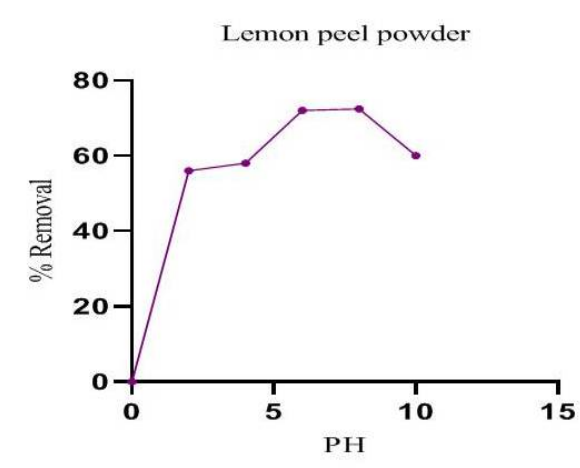

Fig-7: Impact of $\mathrm{p}^{\mathrm{H}}$ on arsenic Biosorption

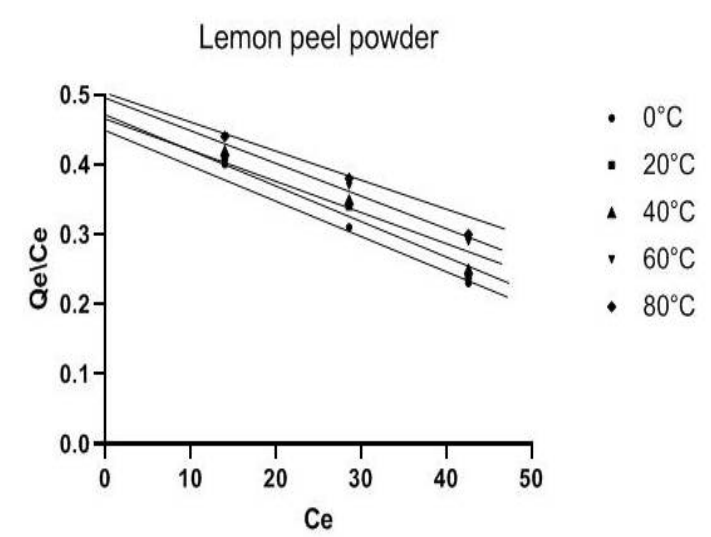

Fig-9: Arsenic removal by the Langmuir Isotherm 


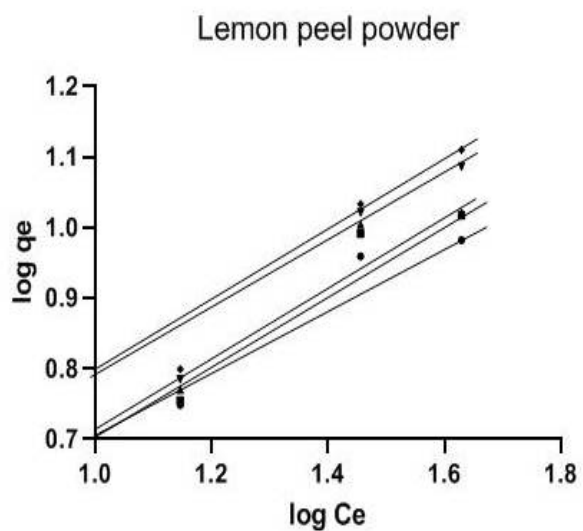

Fig-10:Using the Freundlich biosorption isotherm to remove arsenic from citrus peel powder

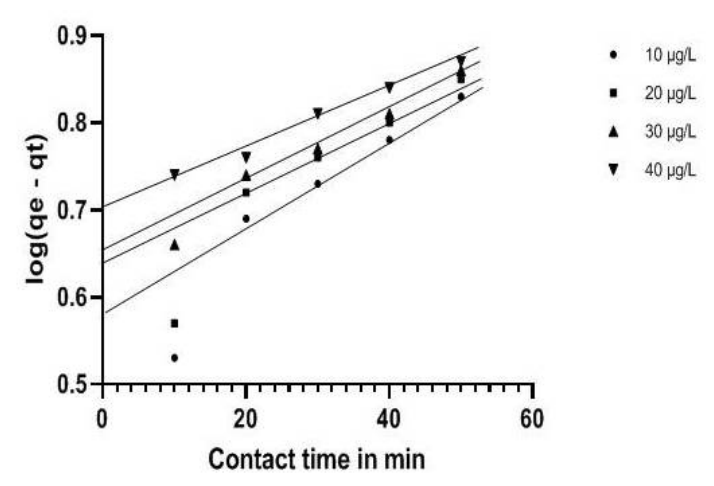

Fig-12: Pseudo first order kinetic

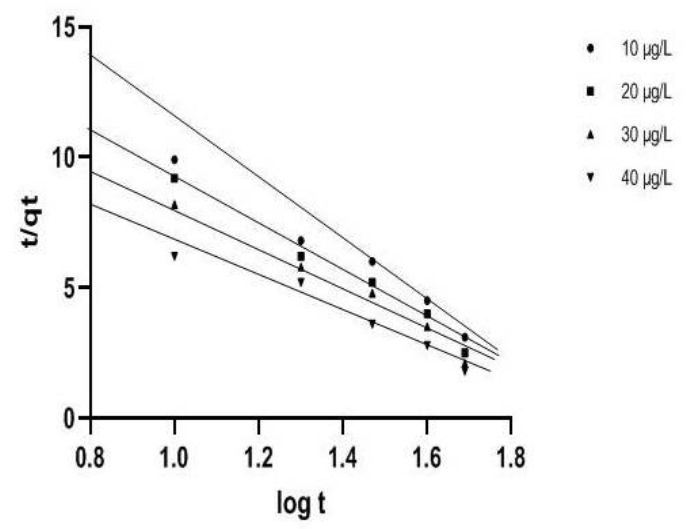

Fig-14: shows the Elovich model.

- $0^{\circ} \mathrm{C}$

- $20^{\circ} \mathrm{C}$

- $40^{\circ} \mathrm{C}$

- $60^{\circ} \mathrm{C}$

- $80^{\circ} \mathrm{C}$

$(80$ Fig-11:Temk Adsorption

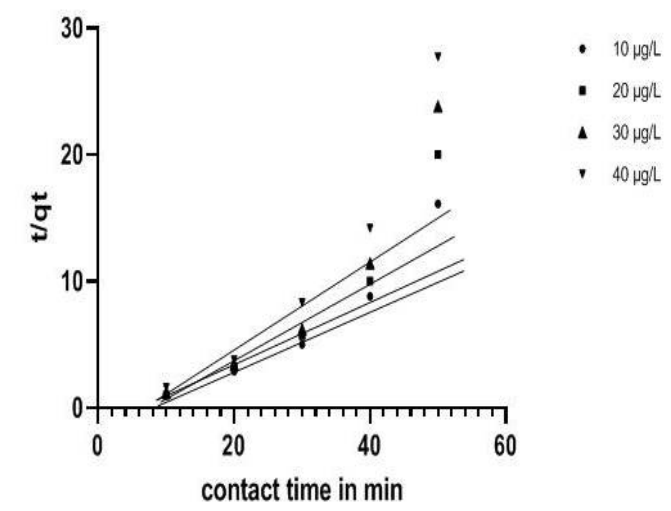

Fig-13: Pseudo second order kinetic

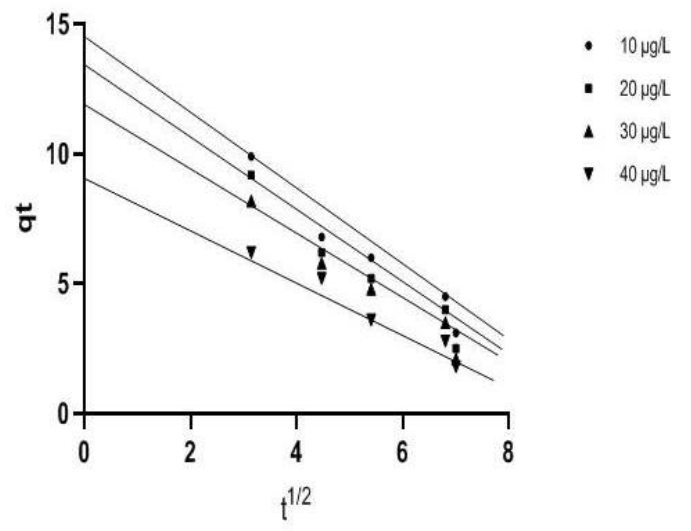

Fig-15: Weber Morris Diffusion Model 


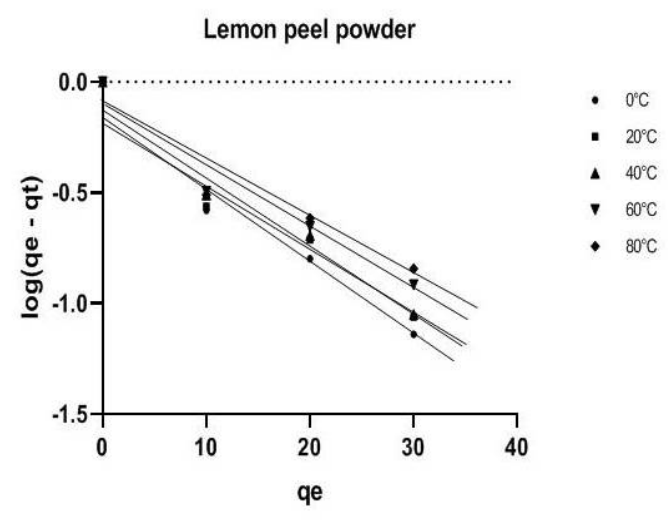

Fig -16: The relationship between $\ln (\mathrm{qe} / \mathrm{ce})$ and $\ln (\mathrm{qe} / \mathrm{ce})$.

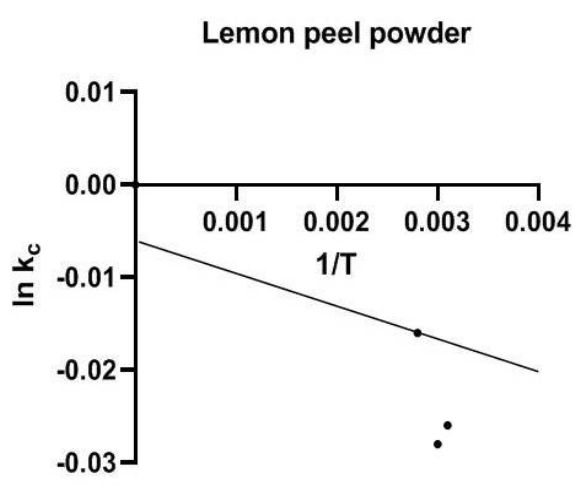

Fig-17: shows the relationship between $\ln (\mathrm{Kc}), 1 / \mathrm{T}$, and qe for the removal of

Arsenic by lemon peel powder. 